\title{
An Optimized Protocol to Increase Virus-Induced Gene Silencing Efficiency and Minimize Viral Symptoms in Petunia
}

\author{
Shaun R. Broderick • Michelle L. Jones
}

Published online: 3 September 2013

(C) The Author(s) 2013. This article is published with open access at Springerlink.com

\begin{abstract}
Virus-induced gene silencing (VIGS) is used to down-regulate endogenous plant genes. VIGS efficiency depends on viral proliferation and systemic movement throughout the plant. Although tobacco rattle virus (TRV)-based VIGS has been successfully used in petunia (Petunia $\times$ hybrida), the protocol has not been thoroughly optimized for efficient and uniform gene down-regulation in this species. Therefore, we evaluated six parameters that improved VIGS in petunia. Inoculation of mechanically wounded shoot apical meristems induced the most effective and consistent silencing compared to other methods of inoculation. From an evaluation of ten cultivars, a compact petunia variety, 'Picobella Blue', exhibited a 1.8-fold higher $C H S$ silencing efficiency in corollas. We determined that $20^{\circ} \mathrm{C}$ day $/ 18^{\circ} \mathrm{C}$ night temperatures induced stronger gene silencing than $23{ }^{\circ} \mathrm{C} / 18{ }^{\circ} \mathrm{C}$ or $26^{\circ} \mathrm{C} /$ $18^{\circ} \mathrm{C}$. The development of silencing was more pronounced in plants that were inoculated at 3-4 versus 5 weeks after sowing. While petunias inoculated with pTRV2-NbPDS or pTRV2-PhCHS showed very minimal viral symptoms, plants inoculated with the pTRV2 empty vector (often used as a control) were stunted and developed severe necrosis, which often led to plant death. Viral symptoms were eliminated by developing a control construct containing a fragment of the green fluorescent protein (pTRV2-sGFP). These optimization steps increased the area of chalcone synthase (CHS) silencing by $69 \%$ and phytoene desaturase (PDS) silencing by $28 \%$. This improved VIGS protocol, including the use of the pTRV2-sGFP control plants, provides stronger down-
\end{abstract}

Electronic supplementary material The online version of this article (doi:10.1007/s11105-013-0647-3) contains supplementary material, which is available to authorized users.

S. R. Broderick · M. L. Jones $(\square)$

Department of Horticulture and Crop Science, Ohio Agricultural

Research and Development Center, The Ohio State University, 1680

Madison Avenue, 214A Williams Hall, Wooster, OH 44691, USA

e-mail: jones.1968@osu.edu regulation for high-throughput analyses of gene function in petunia.

Keywords Chalcone synthase - Green fluorescent protein . Phytoene desaturase $\cdot$ Solanaceae $\cdot$ Tobacco rattle virus . Necrosis

\section{Introduction}

In reverse genetic studies, one method of evaluating gene function is to down-regulate endogenous genes and observe the resulting phenotypes. This can be accomplished by transforming plant cells with an RNA interference (RNAi) silencing construct, followed by tissue culture regeneration (Benedito et al. 2004). This elicits gene silencing through mRNA degradation and translational inhibition in a process called post-transcriptional gene silencing (PTGS; Al-Kaff et al. 1998; Napoli et al. 1990; Watson et al. 2005) or RNAi (Fire et al. 1998; Muruganantham et al. 2009). As an alternative method to down-regulate genes, engineered viruses that contain a fragment of a plant gene of interest (GOI) can be used to cause down-regulation of the plant's endogenous gene using virus-induced gene silencing (VIGS; Kumagai et al. 1995; Van Kammen 1997). This process does not require plant regeneration through tissue culture, thereby, decreasing the time needed to evaluate gene function in many species. VIGS efficiency is limited by the severity of viral infection, and incomplete viral infection will leave sections of the plant without gene down-regulation (Caplan and Dinesh-Kumar 2006; Muruganantham et al. 2009). The ability and extent of the virus to elicit PTGS can vary greatly and differs with environmental conditions and inoculation methods ( $\mathrm{Lu}$ et al. 2003). It is therefore necessary to optimize the VIGS protocol for each crop to maximize silencing (Burch-Smith et al. 2004). 
Silencing of specific genes, such as phytoene desaturase $(P D S)$ and chalcone synthase $(C H S)$, provide visual indicators for the location and extent of gene silencing throughout the plant (Chen et al. 2004; Kumagai et al. 1995). PDS is involved in carotenoid biosynthesis (Grünewald et al. 2000; Kumagai et al. 1995), and photobleaching (i.e., chlorophyll degradation resulting in photosynthetic tissue turning white) occurs when PDS transcripts are down-regulated (Dalmay et al. 2000; Kumagai et al. 1995). PDS silencing is therefore used as a visual indicator of PTGS in green, vegetative tissues. CHS is involved in the formation of anthocyanin pigments, and serves as a visual indicator of gene silencing in floral and fruit tissues. Pigmented petals turn white when CHS is downregulated in petunia (Chen et al. 2004; Napoli et al. 1990; Spitzer et al. 2007).

Tobacco rattle virus (TRV) has been successfully used as a VIGS vector in many solanaceous species (Hartl et al. 2008; Liu et al. 2002a, b; Saedler and Baldwin 2004) and also in Arabidopsis thaliana (Burch-Smith et al. 2006; Wang et al. 2006), Gerbera hybrida (gerber daisy; Deng et al. 2012), Fragaria $\times$ ananassa (strawberry; Hoffmann et al. 2006), Aquilegia vulgaris and $A$. coerulea (columbine; Gould and Kramer 2007; Sharma and Kramer 2013), Eschscholzia californica (california poppy; Wege et al. 2007), and Papaver somniferum (opium poppy; Hileman et al. 2005). The experimental methods vary among species, even within Solanaceae. For example, in Solanum tuberosum (potato), optimized silencing is achieved with sap inoculation and growing temperatures of $16-18^{\circ} \mathrm{C}$ (Brigneti et al. 2004). In Nicotiana benthaminana, silencing can be achieved by inoculating seedlings at the fourleaf stage via agroinfiltration (i.e., infiltrating inoculum into the leaf with a needleless syringe) and growing plants at $25^{\circ} \mathrm{C}$ (Liu et al. 2002b), while in S. lycopersicum, more efficient silencing is achieved using an infiltration spray method (Liu et al. 2002a) or vacuum infiltration (Wu et al. 2011). In Petunia $\times$ hybrida, VIGS has been effectively conducted by using agroinfiltration at the 4-6 leaf stage and growing plants at $25{ }^{\circ} \mathrm{C}$ day $/ 20{ }^{\circ} \mathrm{C}$ night temperatures (Chen et al. 2004). Apical meristem inoculation was also effective at promoting gene silencing (Spitzer et al. 2007), but a comparative study of different inoculation techniques in petunia has not been reported.

TRV-based VIGS has been used in petunia to study flower senescence-related genes (Chen et al. 2004; Xu et al. 2007), floral scent (Spitzer et al. 2007; Spitzer-Rimon et al. 2010), and developmental genes (Chen et al. 2005; Jiang et al. 2011). In typical VIGS experiments, control plants are inoculated with both pTRV1 and empty vector pTRV2. Viral symptoms are rarely reported in the TRV-based VIGS experiments and usually consist of leaf mottling or diffuse mosaic patterns (e.g., Sharma et al. 2003; Chen et al. 2004). In petunia, no severe viral symptoms have been reported to date from pTRV2 empty vector (Chen et al. 2004, 2005; Jiang et al. 2011; Spitzer et al. 2007; SpitzerRimon et al. 2010; Xu et al. 2007), but viral symptoms of stunting and necrosis have been reported in $S$. lycopersicum (Wu et al. 2011), S. nigrum (Hartl et al. 2008), S. okadae (Brigneti et al. 2004), and S. tuberosum (Ghazala and Varrelmann 2007). We observed that petunias inoculated with the pTRV2 empty vector consistently exhibited severe viral symptoms including lesions, necrosis, chlorosis, stunting and death. TRV symptoms are nearly eliminated when pTRV2 contains a gene insert (e.g., $P D S$ or any GOI). In S. lycopersicum (Wu et al. 2011) and S. nigrum (Hartl et al. 2008), symptoms are eliminated or greatly minimized by inserting a fragment of nonplant DNA into the multiple cloning site of pTRV2. Without eliminating these severe viral symptoms, it becomes nearly impossible to design experiments that contain the proper controls needed for phenotyping VIGS plants.

Although excellent work has been conducted to lay the foundation for VIGS analyses in petunia, other inoculation techniques and growing conditions need to be investigated to further optimize the protocol. This will result in more rapid, widespread and consistent gene silencing in petunia and increase the usefulness of this technique for gene functional analyses. Here, we report an optimized method and stage of development for inoculation, as well as cultivars and environmental growing conditions that further increase the reliability and extent of VIGS in petunia. The severity of viral symptoms observed in control plants (i.e., those inoculated with pTRV2 empty vector) has also increased as we have optimized silencing efficiency, so we have developed a new control vector that nearly eliminates viral symptoms in petunia plants.

\section{Materials and Methods}

\section{Plant Materials and Growing Conditions}

Petunia $\times$ hybrida seeds were sown in plug trays on soil-less mix (Pro-mix BX, Premier Horticulture, Quebec, Canada) and grown under florescent grow lights. Cultivars included 'Carpet Blue', 'Dreams Midnight', 'Dreams Pink', 'Fantasy Blue', 'Madness Midnight', 'Sophistica Blue Morn', 'Picobella Blue', 'Picobella Red', 'Primetime Blue' and 'Ultra Blue'. After 34 weeks, plants were transplanted into 8 -cm square pots and moved to growth chambers (Conviron; Manitoba, Canada). Plants were grown under metal halide lights at approximately $150 \mu \mathrm{mol} \mathrm{m}^{-2} \mathrm{~s}^{-1}$ for 16-h light and 8-h dark cycles with an average relative humidity of $69 \%$. Temperatures are noted for each of the experiments described below. Plants were fertilized with $250 \mathrm{mg} \mathrm{l}^{-1} \mathrm{~N}$ from Peters Professional 20-10-20 (The Scotts Co., Marysville, OH, USA).

Plasmid Construction

For experiments, we utilized TRV-based vectors, pTRV1 (pYL192; GenBank accession AF406990) and pTRV2 
(pYL156; accession AF406991), which were described by Liu et al. (2002b). Briefly, pTRV1 is a vector containing RNA1 partite from TRV, and pTRV2 contains a modified RNA2 partite where the genes involved in nematode transmission were replaced with a multiple cloning site. The coat protein in TRV2 is regulated by two $35 \mathrm{~S}$ promoters. These vectors, pTRV1 and pTRV2, are binary and must be combined at the time of inoculation. For quantification of gene silencing in leaves we utilized pTRV2-NbPDS and for flowers we used pTRV2-PhCHS. pTRV2-NbPDS was obtained from Dr. Sophien Kamoun (Sainsbury Laboratory, Norwich, UK), and pTRV2-PhCHS was constructed using primers designed by Chen et al. (2004). PDS from $N$. benthamiana and $P . \times$ hybrida are $95 \%$ identical at the nucleotide level, and the NbPDS efficiently induces photobleaching in many solanaceous species (Senthil-Kumar et al. 2007). We designed primers (Table S1) that amplified different sized fragments (198, 265 and $383 \mathrm{bp})$ of soluble green fluorescent protein (sGFP) from pFELV (Hernandez-Garcia et al. 2010). These fragments were digested using $X b a \mathrm{I}$ and $\mathrm{Bam} \mathrm{HI}$ restriction enzymes and cloned into pTRV2. Using electroporation (Electroporator 2510; Eppendorf, Hamburg, Germany), all constructs were transformed into Agrobacterium tumefaciens strain GV3101 and grown on selective Luria-Bertani (LB) agar plates containing $25 \mathrm{gg} \mathrm{ml}^{-1}$ gentamycin, $50 \mu \mathrm{g} \mathrm{ml}$ kanamycin and $10 \mu \mathrm{g} \mathrm{ml}^{-1}$ rifampicin. These antibiotic concentrations were used in all selective media.

\section{Inoculum Preparation}

Single colonies for each construct were inoculated in glass culture tubes containing $3 \mathrm{ml}$ of selective LB-MES broth (10 mM MES, pH 5.7) and grown for $24 \mathrm{~h}$ at $30^{\circ} \mathrm{C}$. Cultures were diluted 10-fold with LB-MES broth containing $20 \mu \mathrm{M}$ acetosyringone and were grown to an $\mathrm{OD}_{600}$ of 0.8-1.0. Cells were collected at $4{ }^{\circ} \mathrm{C}$ at $4,000 \times g$ and re-suspended in agroinduction media (10 $\mathrm{mM}$ MES, $10 \mathrm{mM} \mathrm{MgCl}_{2}$ and $200 \mu \mathrm{M}$ acetosyringone) to an $\mathrm{OD}_{600}$ of 2.0. Inocula were then incubated in the dark at $22{ }^{\circ} \mathrm{C}$ overnight (approximately $16 \mathrm{~h}$ ). Just prior to inoculation, pTRV1 cultures were mixed with pTRV2 (or TRV2 constructs) cultures in a 1:1 ratio. Mock inoculated (i.e., agroinduction media without $A$. tumefaciens), empty vector pTRV2, pTRV2-PhCHS and pTRV2-NbPDS were used in all experiments, unless noted.

\section{Inoculation Methods}

In a growth chamber, petunia 'Primetime Blue' plants were grown at $24{ }^{\circ} \mathrm{C}$ day $/ 20{ }^{\circ} \mathrm{C}$ night. Three-week-old plants were inoculated by one of four methods. Seven to eight plants were used for each treatment. For the apical meristem application, the shoot apical meristem was removed using forceps and three to five drops (approximately $150 \mu \mathrm{l}$ ) of inoculum was applied using a disposable dropper. For agroinfiltration, we used a 1-ml syringe without a needle and injected inoculum into the lowest two to three leaves on each plant to the point of cell saturation. For vacuum infiltration, we used a Maxima C Plus vacuum pump (model M4C; Fisher Scientific, Pennsylvania, USA) and a desiccator. The soil was covered with cheese cloth and secured with rubber bands. Inside of a desiccator, plants were inverted and submerged into a glass beaker filled with inoculum, and a vacuum was applied until air bubbles appeared on the sides of the beaker. After 2 min, the vacuum was released and plants were left in the inoculum for an additional $2 \mathrm{~min}$. For the agrodrench, $25 \mathrm{ml}$ of inoculum was applied directly to the soil near the crown of the plant. After inoculation, all plants were covered with clear plastic domes and kept in the dark for $24 \mathrm{~h}$.

\section{Cultivar Optimization}

All ten cultivars were grown at $24{ }^{\circ} \mathrm{C}$ day $/ 20{ }^{\circ} \mathrm{C}$ night in a growth chamber. Three-week-old plants $(n=6)$ were inoculated using the apical meristem application.

\section{Temperature Optimization}

Petunia 'Picobella Blue' plants were grown at daytime temperatures of $20{ }^{\circ} \mathrm{C}, 23{ }^{\circ} \mathrm{C}$, and $26{ }^{\circ} \mathrm{C}$ with a nighttime temperature of $18{ }^{\circ} \mathrm{C}$. There were two replicates per temperature (i.e., two growth chambers for each temperature for a total of six chambers), and eight plants per replicate. Three-week-old plants were inoculated using the apical meristem application.

\section{Seedling Age at Inoculation}

Petunia 'Picobella Blue' seeds were sown on the same date. They were inoculated at 3, 4, and 5 weeks after the sow date. Plants $(n=10)$ were grown in a growth chamber at $20^{\circ} \mathrm{C}$ day/ $18{ }^{\circ} \mathrm{C}$ night and inoculated using the apical meristem application.

\section{Control Construct Evaluation}

Four-week-old petunia 'Picobella Blue' seedlings $(n=6)$ were inoculated with pTRV1/pTRV2 empty vector, pTRV1/ pTRV2-sGFP-1 (198 bp), pTRV1/pTRV2-sGFP-2 (265 bp), pTRV1/pTRV2-sGFP-3 (383 bp) and agroinduction media (to serve as a mock inoculated control). Plants were grown at $20{ }^{\circ} \mathrm{C}$ day/ $18{ }^{\circ} \mathrm{C}$ night and inoculated using the apical meristem application. Viral lesions (i.e., necrotic regions) were counted daily as they appeared after inoculation. Two young, fully expanded petunia leaves (two to three whorls down from a shoot meristem) were pooled from six plants in each treatment for RNA extraction. 


\section{RT-qPCR Expression Analysis}

To correlate CHS and PDS transcript abundance with photobleaching and floral pigment loss, six individual leaves and five individual flowers ranging in phenotypic extremes (from $100 \%$ white to nearly $100 \%$ pigmented) were collected, individually imaged, and flash frozen. Reverse transcription quantitative PCR (RT-qPCR) was used to measure transcript abundance of TRV coat protein and PDS in leaves and CHS in corollas. Total RNA was extracted using TRIzol reagent (Invitrogen, Carlsbad, CA, USA) and RNA was treated with RQ1 RNase-free DNase (Promega, Madison, WI, USA). cDNA was synthesized from $2 \mu \mathrm{g}$ RNA using the Omniscript RT kit (Qiagen, Valencia, CA, USA). RT-qPCR was performed in a $20 \mu \mathrm{l}$ reaction volume using iQ SYBR Green Master Mix (Bio-Rad, Hercules, CA, USA). One microliter of cDNA was used as template, and all reactions were performed in triplicate. RT-qPCR primers (Table S2) for TRV coat protein, petunia polyubiquitin (UBQ), and petunia actin (PhACTIN) were as previously described by Hartl et al. (2008), Mallona et al. (2010), and Chapin and Jones (2009). $P D S$ and $C H S$ RT-qPCR primers were designed using PrimerQuest (Integrated DNA Technologies, Coralville, IA, USA). PCR for coat protein was conducted after an initial $94{ }^{\circ} \mathrm{C}$ activation for $3 \mathrm{~min}$ for 35 cycles of $94{ }^{\circ} \mathrm{C}$ for $10 \mathrm{~s}$, $60{ }^{\circ} \mathrm{C}$ for $30 \mathrm{~s}, 72{ }^{\circ} \mathrm{C}$ for $15 \mathrm{~s}$ using the iQ5 Thermocycler (Bio-Rad). PDS and CHS PCR was conducted using the following two-step protocol: a $94{ }^{\circ} \mathrm{C}$ activation for $3 \mathrm{~min}$ was followed with 40 cycles of $94{ }^{\circ} \mathrm{C}$ for $10 \mathrm{~s}$ and $62{ }^{\circ} \mathrm{C}$ for $30 \mathrm{~s}$. Melt curves were generated to check amplification specificity. $P D S$ gene expression was normalized to $U B Q$ for each cDNA leaf sample and $C H S$ expression was normalized to PhACTIN for each corolla sample.

\section{Growth Chamber to Greenhouse Transition}

Four-week-old petunia 'Picobella Blue' seedlings were inoculated in the growth chamber and moved to the greenhouse on $0,4,7$ and 10 days after inoculation $(n=8)$. An additional set of inoculated plants were maintained in the growth chamber $\left(20{ }^{\circ} \mathrm{C}\right.$ day $/ 18^{\circ} \mathrm{C}$ night) for the duration of the evaluations. From March 2, 2012 to June 1, 2012, the greenhouse temperatures were set at $20{ }^{\circ} \mathrm{C}$ day $/ 18{ }^{\circ} \mathrm{C}$ night and maintained an average temperature of $27.6 \pm 6.4{ }^{\circ} \mathrm{C}$ day $/ 19.6 \pm 3.0{ }^{\circ} \mathrm{C}$ night. Relative humidity was approximately $44 \%$, and average light levels were $155 \mu \mathrm{mol} \mathrm{m} \mathrm{m}^{-2}$.

\section{Gene Silencing Phenotypic Evaluations}

In petunias, silencing $P D S$ causes leaves to turn white and silencing $C H S$ causes pigmented corollas to turn white. We used these phenotypes to measure the extent of gene silencing among the experimental treatments. Equation 1 describes the silencing frequency as the percent of plants that exhibit silencing phenotypes after inoculation with either pTRV1/pTRV2NbPDS or pTRV1/pTRV2-PhCHS. The silencing effectiveness is defined in Eq. 2 as the percent of total leaves or flowers per plant that display silencing phenotypes (Senthil-Kumar et al. 2007). Gene silencing efficiency was calculated using WinCAM image analysis software (Version 2007d; Regent Instruments, Canada) and is defined in Eq. 3. This software allowed us to quantify silencing (areas of white coloration) from images of total leaves or flowers. The image pixels not related to plant tissue (i.e., background pixels) are userdefined and were removed from analysis. To determine the silencing efficiencies of $P D S$, all leaves were harvested from each plant and placed on a flatbed scanner to be imaged. With a digital camera, CHS silencing efficiencies were quantified by photographing each flower from every plant and analyzing each flower individually. These individual images were pooled by plant for statistical analysis.

$$
100 \times(\text { silencing frequency })=\frac{\text { plants with visible silencing }}{\text { total plants treated }}
$$

$100 \times($ silencing effectiveness $)=\frac{\text { leaves or flowers with visible silencing }}{\text { total leaves or flowers }}$

$100 \times($ silencing efficiency $)=\frac{\text { white colored pixels }}{(\text { total pixels }- \text { background pixels })}$

\section{Data Analysis}

All statistical analyses were conducted in SAS 9.3 (SAS Institute Inc., Cary, NC, USA). For parametric data, statistical differences were determined using Proc Glimmix with a least squares means separation with $\alpha=0.05$. Data points sharing the same letter are not statistically different. Statistical differences for non-parametric data were determined using a Kruskal-Wallis test. Growth chamber temperature data were blocked by chamber (i.e., replicate) and analyzed using Proc Glimmix as described previously. Correlation coefficients $(r)$ between transcript abundance and silencing phenotypes were determined using Proc Corr.

\section{Results}

Optimizing the Inoculation Technique

In VIGS experiments, Agrobacterium is used to transform T-DNA containing the viral genome and a GOI fragment into plant cells. Inoculation methods affect the success of DNA transfer and the silencing efficiency. We tested the efficacy of four inoculation methods including 
apical meristem application, agrodrench, agroinfiltration, and vacuum infiltration (Burch-Smith et al. 2004; Liu et al. 2002a, 2002b; Ryu et al. 2004; Wang et al. 2006). Petunias inoculated with pTRV2-NbPDS showed photobleaching of the leaves, which is typical of $P D S$ silencing (i.e., green vegetative tissue turning white). Differences in the amount and timing of photobleaching were observed among techniques (Fig. S1 and Fig. 1). Apical meristem inoculated plants displayed photobleaching 3 days earlier, on average, than the other techniques investigated (Fig. S1). Photobleaching frequency (i.e., percent of photobleached plants; Eq. 1) was $100 \%(8 / 8)$ for all techniques, except agrodrench, which had symptoms of photobleaching in only $25 \%(2 / 8)$ of the plants (Fig. 1a). Photobleaching effectiveness (i.e., percent of photobleached leaves per plant; Eq. 2) provided more information about the extent of photobleaching throughout the plant. The agrodrench method also resulted in fewer photobleached leaves per plant (an average of $39 \%$ lower) than the other techniques (Fig. 1b). Leaves varied from completely white to having only a few small photobleached areas (Fig. 2). A more
PDS silencing (pTRV2-NbPDS)

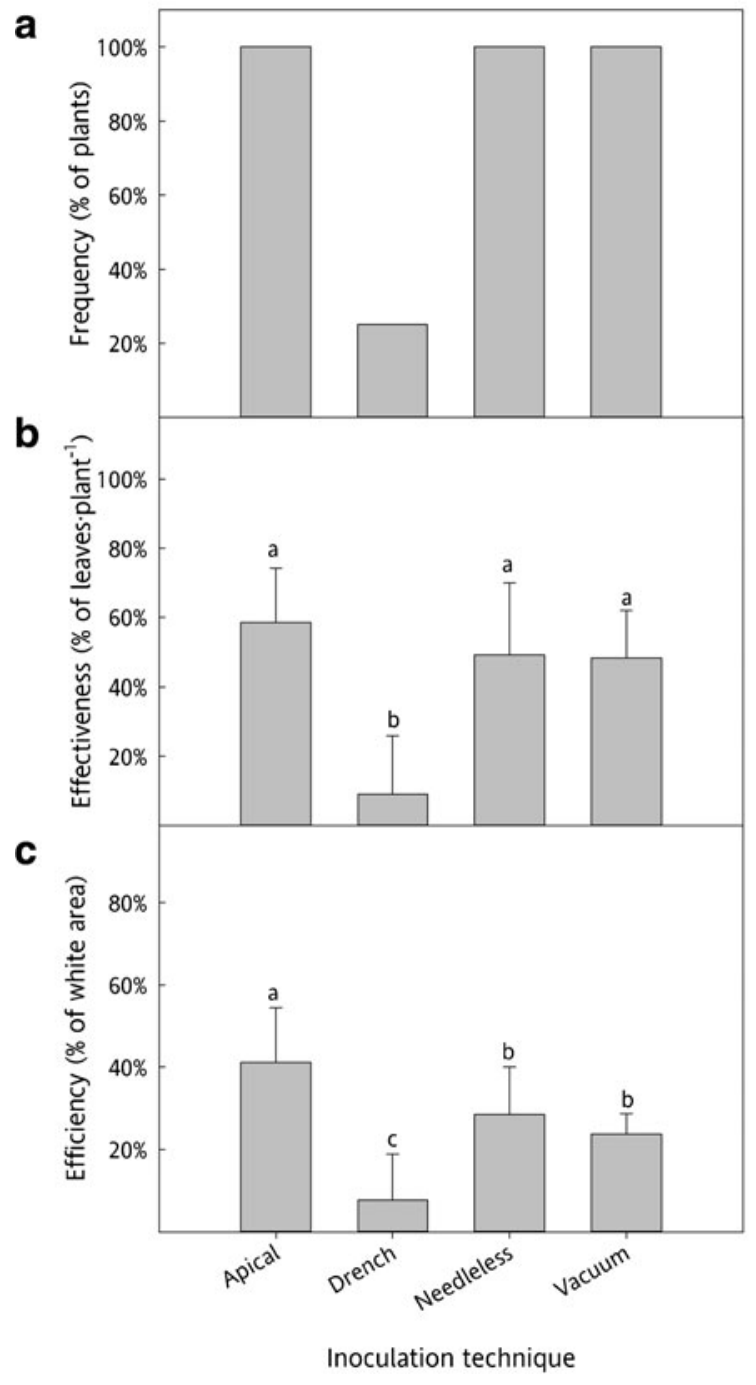

Fig. 1 Effects of inoculation technique on PDS and CHS silencing phenotypes. Petunia $\times$ hybrida 'Primetime Blue' seedlings were inoculated with pTRV2-NbPDS or pTRV2-PhCHS using apical meristem application (apical), agrodrench (drench), agroinfiltration (needleless), or vacuum infiltration (vacuum). Gene silencing was estimated by photobleaching (PDS silencing) and $C H S$ silencing. Letters above the bars $(n=7-8)$ display statistical difference based on least squares means separation. a $P D S$ silencing frequency: percent of plants that exhibited photobleaching. b $P D S$ silencing effectiveness: percent of leaves per

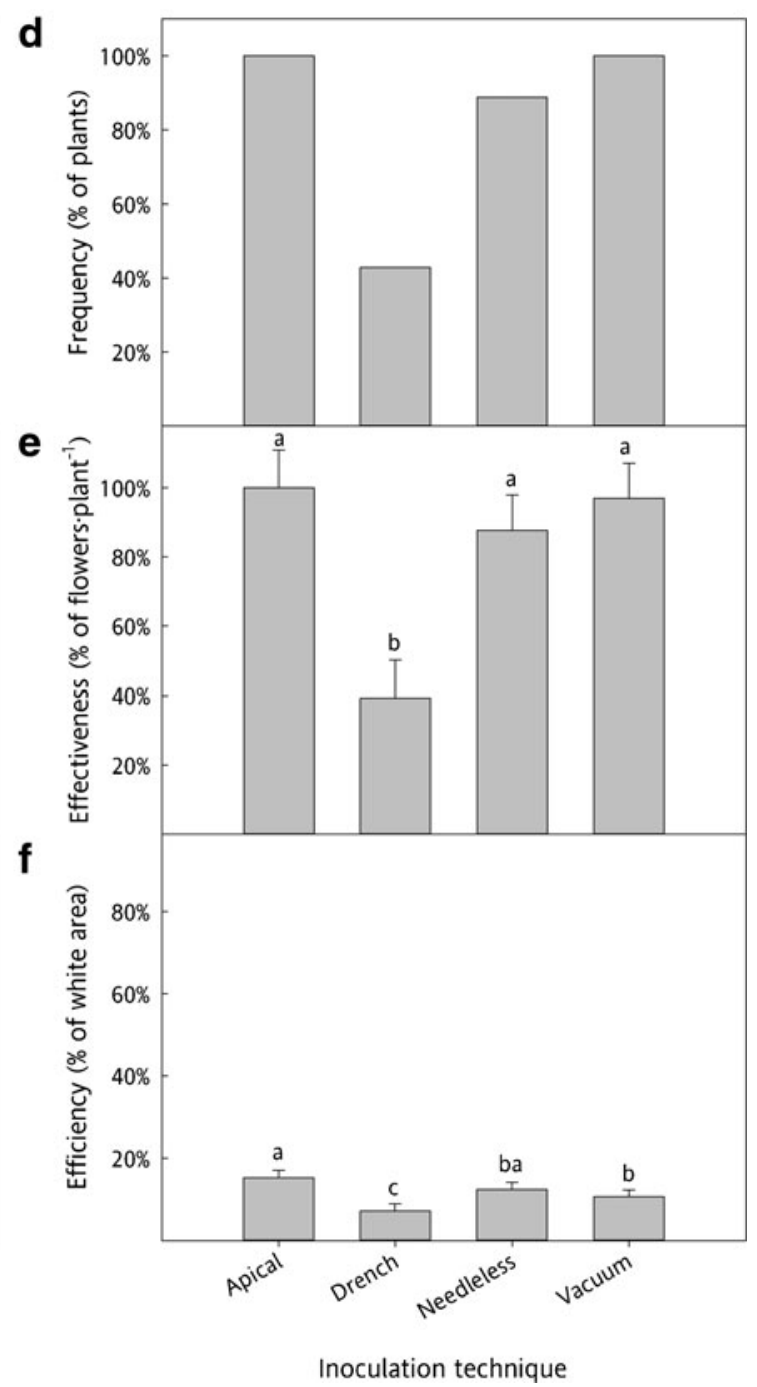

plant with photobleaching. c $P D S$ silencing efficiency: extent of photobleaching per leaf quantified using WinCAM version 2007d (Regent Instrument Canada Inc.) image analysis software. d CHS silencing frequency: percent of plants that had corollas with white sectors. e $C H S$ silencing effectiveness: percent of flowers per plant with white sectors. $\mathbf{f}$ CHS silencing efficiency: extent of white sectoring per flower quantified using WinCAM. b, c Each bar represents the mean \pm SD. e, f Error bars represent SE 
quantitative measurement was therefore obtained by using image analysis software (WinCAM) to calculate the total area of photobleached leaf tissue on a plant, allowing for a more precise comparison of silencing efficiency between the inoculation treatments. Photobleaching efficiency (i.e., percent of photobleaching across all leaves of a plant; Eq. 3) was an average of $13 \%$ higher for the apical meristem inoculation than the other inoculation techniques tested (Fig. 1c).

Inoculation techniques were further evaluated with pTRV2-PhCHS, which caused pigmented petals to turn white. All inoculation techniques produced some corollas with white sectors. CHS silencing frequency was $100 \%$ for vacuum infiltration and the apical meristem application. CHS silencing was observed in only $43 \%(3 / 7)$ and $88 \%(7 / 8)$ of the plants from the agrodrench and agroinfiltration techniques, respectively (Fig. 1d). No statistical differences in $C H S$ silencing effectiveness were observed between the apical meristem application, agroinfiltration, and vacuum infiltration (Fig. 1e). However, agrodrench had an average of $39 \%$ of flowers per plant showing silencing symptoms. $C H S$ silencing efficiency was highest in plants inoculated by apical meristem application and agroinfiltration (Fig. 1f). Overall, the apical meristem application resulted in the greatest silencing in both leaves and corollas; therefore, apical meristem inoculations were used throughout the remaining experiments.

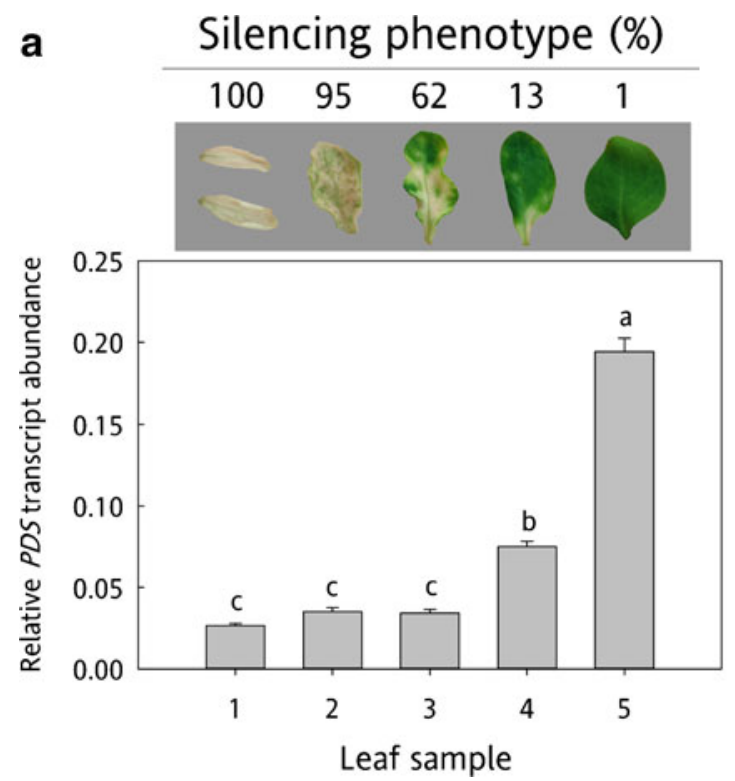

Fig. 2 Phenotypic silencing and transcript abundance of $P D S$ and $C H S$. a Six leaves ranging in the extent of photobleaching were collected from a single Petunia $\times$ hybrida 'Picobella Blue' plant that was inoculated with pTRV2-NbPDS. Photobleaching was quantified using WinCAM version 2007d (Regent Instrument Canada Inc.) image analysis software and is displayed above each leaf sample. Total RNA was extracted from each leaf separately for RT-qPCR analysis except for the two most highly photobleached leaves (i.e., leaf sample 1), which were pooled to obtain a sufficient quantity of RNA. PDS transcript abundance was normalized
Correlations Between Phenotypic Results and Transcript Abundance

It has been established in the literature that photobleaching and anthocyanin loss result from down-regulating $P D S$ and CHS , respectively (Napoli et al. 1990; Kumagai et al. 1995; Dalmay et al. 2000; Chen et al. 2004; Spitzer et al. 2007; Urso et al. 2013). We performed RT-qPCR to verify that our phenotypic observations from plants inoculated with pTRV2NbPDS and pTRV2-PhCHS resulted from silencing PDS and $C H S$. In white leaves, transcript abundance of $P D S$ was reduced by $86 \%$ (compared to a green leaf from the same plant), and in white corollas CHS was reduced by $80 \%$ (compared to a nearly purple flower from the same plant) (Fig. 2). Although significant down-regulation of $P D S$ and $C H S$ were measured in white plant tissues, there was no significant correlation between transcript abundance and silencing phenotypes for either $P D S(r=0.813, P=0.09)$ or CHS ( $r=0.720, P=0.17$ ) in tissues ranging in visual silencing phenotype (Fig. 2). Additionally, the RT-qPCR data indicated no further reduction in $P D S$ transcript abundance among leaf samples that had photobleaching efficiencies ranging from $62 \%$ to $100 \%$. In corolla samples, there was no difference between CHS transcript abundance in a flower that was $100 \%$ white, versus a flower with $21 \%$ white sectoring. In contract, CHS transcript abundance in flowers with white sectoring of

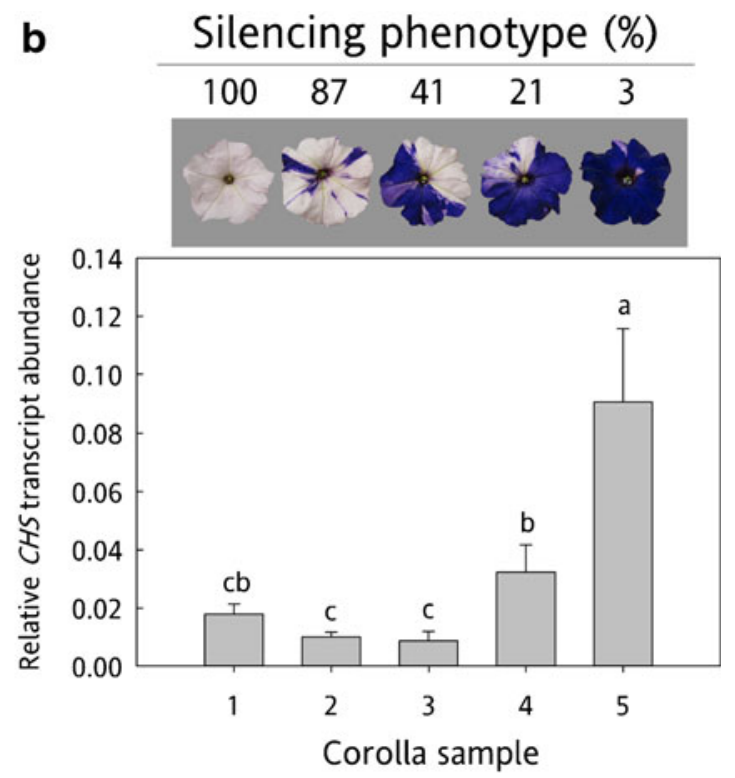

to $U B Q$. b Five flowers varying in the amount of white sectoring were collected from a single Petunia $\times$ hybrida 'Picobella Blue' that was inoculated with pTRV2-PhCHS. The white sectoring values above each flower sample were quantified using WinCAM. Total RNA was extracted from each flower separately for RT-qPCR analysis. $\mathrm{CHS}$ transcript abundance was normalized to PhACTIN. a, b RT-qPCR samples were run in triplicate. Each bar represents the mean relative transcript abundance \pm $\mathrm{SD}$. The tissue images and the silencing percentages correspond to the bar graphs below 
$41 \%$ and $87 \%$ were significantly lower than flowers with only $21 \%$ and $3 \%$ white sectoring. Therefore, RT-qPCR can quantify general gene down-regulation of $P D S$ and $C H S$ in plants with silencing phenotypes, but is unable to accurately predict the mRNA levels that are actively translated in leaf and corolla tissues with high silencing efficiency.

\section{Petunia Cultivar Selection}

Differences in silencing have been observed among petunia cultivars (Chen et al. 2004). Therefore, ten cultivars were evaluated to determine differences in silencing when using the apical meristem inoculation and to identify plant growth characteristics conducive to growth and flowering in growth chambers. Specifically, we evaluated $P D S$ silencing efficiency, time after inoculation to first visible photobleaching, $\mathrm{CHS}$ silencing efficiency, shoot length, shoot dry weight, corolla fresh weight, and time to flower (Table 1). We observed photobleaching and $\mathrm{CHS}$ silencing (Fig. 3) in all petunia cultivars that were evaluated. To determine statistical differences, a least squares means separation was performed on the results of each criterion, and a rating of one (best) to four (worst) was assigned. These scores were summed to determine the cultivar(s) with the best silencing and growth habit (Table 1).

Petunia 'Picobella Blue' received the lowest total score of 15 in the cultivar selection, identifying it as the best candidate for VIGS experiments. It received the best score for strong CHS silencing in flowers (Fig. 3, Table 1) and one of the best ratings for shoot dry weight, because of its compact growth habit. It ranked lower in the category of corolla fresh weight because of its reduced flower size, and it was one of the later cultivars to begin flowering. Other cultivars that received a score under 16 included 'Carpet Blue', 'Fantasy Blue' and 'Primetime Blue'. Cultivars 'Dreams Pink' and 'Ultra Blue' received a total rating above 20 , and performed poorly in many of the ranking categories (Table 1). Petunia 'Picobella Blue' was used in the remaining optimization experiments.

\section{Temperature Optimization}

Temperature can significantly affect VIGS efficiencies (Burch-Smith et al. 2004; Wang et al. 2006). An evaluation of the optimal growing temperatures for VIGS experiments was carried out in environmentally controlled growth chambers. One hundred percent of the plants $(8 / 8)$ grown at daytime temperatures of $20^{\circ} \mathrm{C}, 23{ }^{\circ} \mathrm{C}$ and $26{ }^{\circ} \mathrm{C}\left(18{ }^{\circ} \mathrm{C}\right.$ nighttime temperature) (Fig. 4a, d) showed silencing of $P D S$ and $C H S$. While the percentage of flowers showing CHS silencing (i.e., effectiveness; Fig. 4e) was similar between plants grown at the three different temperatures, the percentage of leaves showing photobleaching was $12 \%$ higher in plants grown at $20{ }^{\circ} \mathrm{C}$ (Fig. 4b). Both $P D S$ and $C H S$ silencing efficiencies were greater in plants grown at $20{ }^{\circ} \mathrm{C}$ compared to plants grown at $23{ }^{\circ} \mathrm{C}$ and $26^{\circ} \mathrm{C}$ daytime temperatures (Fig. $4 \mathrm{c}, \mathrm{f}$ ).

\section{Seedling Age at Inoculation}

Ten of ten plants (100\% frequency) inoculated with pTRV2$N b P D S$ displayed leaf photobleaching regardless of seedling age at the time of inoculation (Fig. 5a). CHS silencing frequency in pTRV2-PhCHS plants was $100 \%$ (10 of 10) for all plants inoculated at 3 and 4 weeks after sowing, but only $90 \%$ ( 9 of 10) of the plants that were inoculated at 5 weeks after

Table 1 Petunia cultivar evaluation ratings

\begin{tabular}{|c|c|c|c|c|c|c|c|c|c|}
\hline \multirow[b]{2}{*}{ Cultivar } & \multirow[b]{2}{*}{ Corolla color } & \multicolumn{8}{|c|}{ Transformed ratings } \\
\hline & & $\operatorname{PDS}^{\mathrm{a}}$ & Visible PDS $^{\mathrm{b}}$ & $\mathrm{CHS}^{\mathrm{c}}$ & Shoot length & Shoot DW & Corolla FW & Days to flower & Total rating \\
\hline Picobella Blue & Purple & 2.125 & 1.375 & 1 & 2 & 1 & 4 & 3.5 & 15 \\
\hline Carpet Blue & Purple & 2.5 & 2.125 & 2.5 & 2 & 2 & 3 & 1 & 15.125 \\
\hline Primetime Blue & Purple & 1.375 & 2.5 & 4 & 2 & 1.75 & 2.5 & 1 & 15.125 \\
\hline Fantasy Blue & Purple & 1 & 1.375 & 2 & 2 & 1.25 & 3.75 & 4 & 15.375 \\
\hline Dreams Midnight & Purple & 2.5 & 1 & 2.5 & 4 & 4 & 1 & 1.5 & 16.5 \\
\hline Madness Midnight & Purple & 2.5 & 1.375 & 2 & 4 & 2.5 & 3.25 & 1 & 16.625 \\
\hline Picobella Red & Red & 2.875 & 3.25 & 3.5 & 1 & 1.25 & 1.5 & 3.5 & 16.875 \\
\hline Sophistica Blue Morn & Purple/blue & 3.25 & 1.375 & 2.5 & 4 & 4 & 1 & 2.5 & 18.625 \\
\hline Ultra Blue & Purple & 2.125 & 4 & 4 & 2 & 3 & 2 & 3 & 20.125 \\
\hline Dreams Pink & Pink & 4 & 3.625 & 2.5 & 3 & 3.5 & 3.75 & 1 & 21.375 \\
\hline
\end{tabular}

Results from least squares means separation of original measurements were transformed to a rating scale of one (best) to four (worst) to determine the optimal cultivar for VIGS experiments

${ }^{\text {a }} P D S$ silencing (photobleaching) efficiency ratings of cultivars inoculated with pTRV2-NbPDS

${ }^{\mathrm{b}}$ Ratings were based on the number of days until photobleaching was visualized after inoculation with pTRV2-NbPDS

${ }^{\mathrm{c}} \mathrm{CHS}$ silencing efficiency ratings of cultivars inoculated with pTRV2-PhCHS 
Fig. 3 Representative $\mathrm{CHS}$ silencing in ten petunia cultivars. Cultivars were inoculated with pTRV2-PhCHS. Flower corollas are to scale $(\mathrm{cm})$

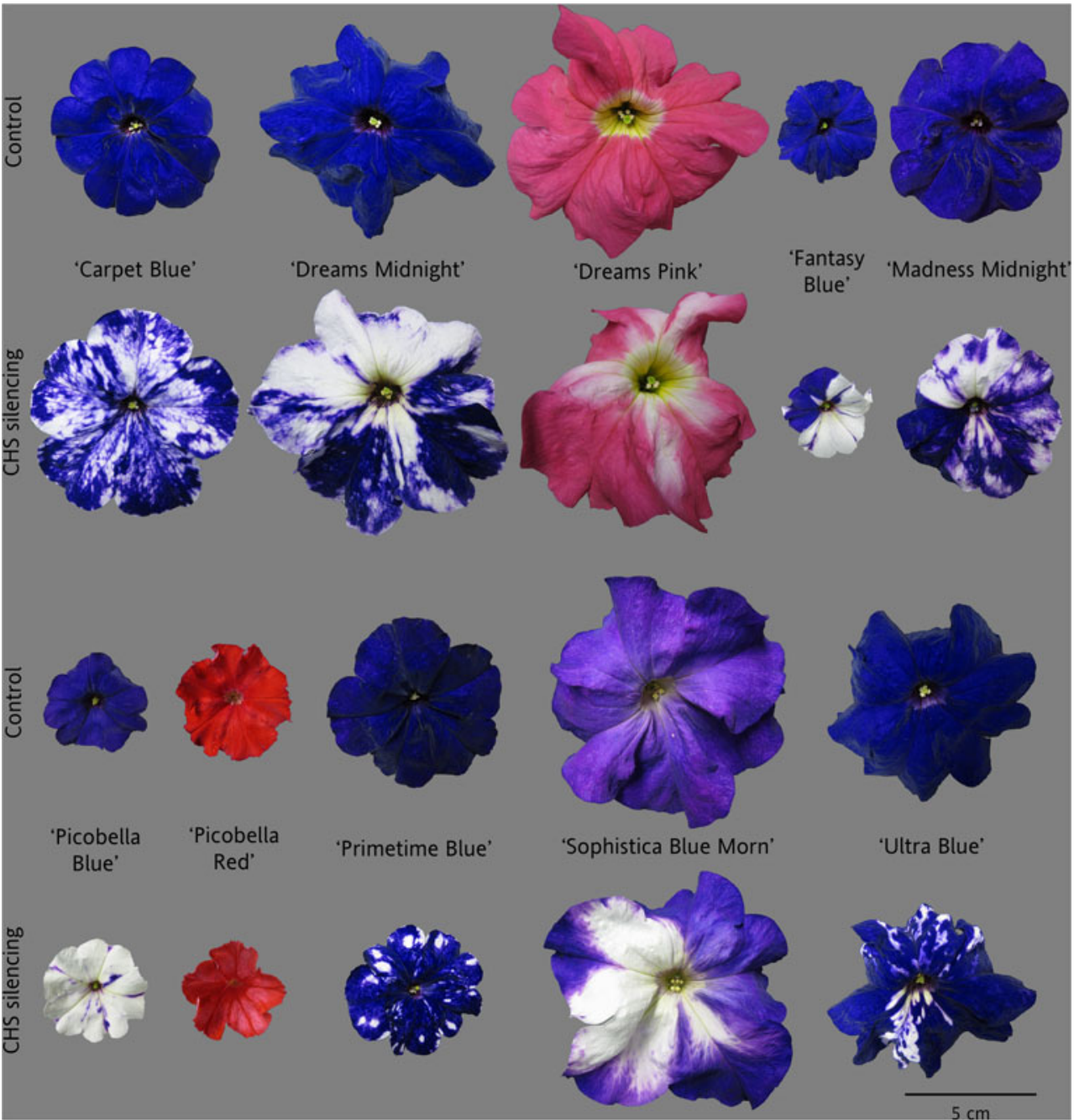

sowing had $\mathrm{CHS}$ silenced flowers (Fig. 5d). The percentage of leaves showing photobleaching was $13 \%$ lower in plants that were inoculated at 5 weeks (PDS effectiveness; Fig. 5b). CHS and $P D S$ silencing efficiencies were also reduced when 5week-old seedlings were inoculated (Fig. 5c, f). The developmental stage of the plant at the time of inoculation did not have any effect on the time to flower, flower numbers, or mature plant weight (FW or DW) (data not shown). Seedlings were inoculated at 4 weeks after germination for the remaining experiments.

\section{Control Vector}

Proper negative controls for VIGS experiments are necessary to accurately phenotype plants when endogenous genes have been silenced. The tobacco rattle virus empty vector (pTRV1/ pTRV2) caused severe necrosis, stunting, flower development delay, and death in petunia (Fig. 6a, b); therefore, it cannot serve as a suitable control. Viral lesions and necrosis developed within 5 days after inoculation and continued to increase in severity over time (Fig. 6a). Inserting a fragment of $s G F P$ eliminated or reduced viral symptoms. $s G F P$ fragment sizes of 265 and $383 \mathrm{bp}$ eliminated necrosis and lesions and nearly eliminated stunting (Fig. 6b). Plants inoculated with the 198bp $s G F P$ fragment still exhibited necrosis and some stunting, but were able to outgrow the viral lesions by 25 days after inoculation (Fig. 6b, c). All TRV inoculated plants were significantly delayed in flowering compared to mock inoculated plants (Fig. 6d). Additionally, pTRV2 empty vector caused a greater delay in flowering than any other TRVVIGS construct. The relative transcript abundance of TRV coat protein (which is indicative of viral titer) was also significantly higher in pTRV2 empty vector plants than plants inoculated with any of the pTRV2-sGFP constructs (Fig. 6e).

Growth Chamber to Greenhouse Transitions

Many VIGS experiments are conducted in environmental growth chambers, but the lack of space in these chambers can severely limit the number of replicates and the number of 
PDS silencing (pTRV2-NbPDS)

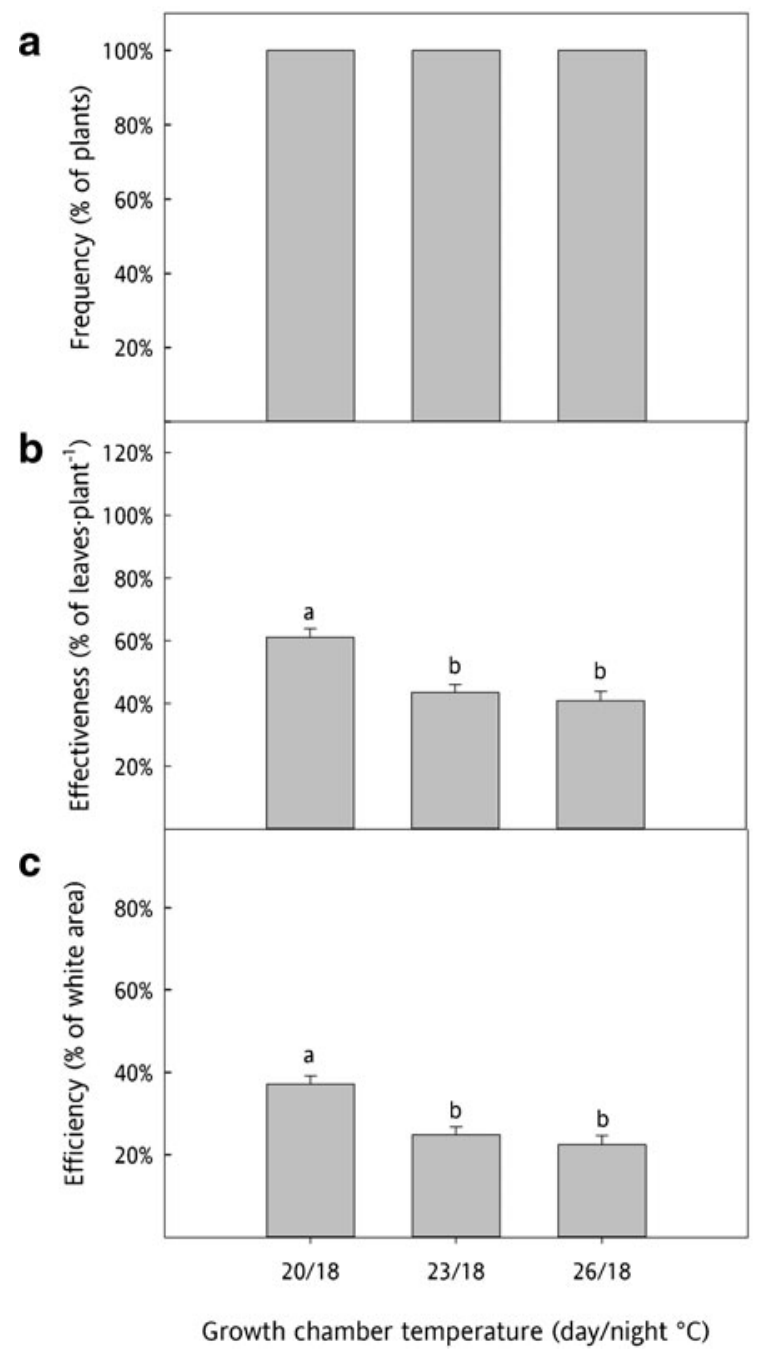

Fig. 4 Evaluation of $P D S$ and $C H S$ silencing phenotypes at three growth chamber daytime temperatures $\left(20^{\circ} \mathrm{C}, 23^{\circ} \mathrm{C}\right.$, and $\left.26^{\circ} \mathrm{C}\right)$ and a nighttime temperature of $18{ }^{\circ} \mathrm{C}$. Petunia $\times$ hybrida 'Picobella Blue' grown at $16-$ $\mathrm{h}$ days were inoculated $(n=8)$ with pTRV2-NbPDS or pTRV2-PhCHS. The area of gene silencing was estimated from photobleaching in leaves ( $P D S$ silencing) and white sectoring in corollas (CHS silencing). a)PDS silencing frequency: percent of plants that exhibited photobleaching. $\mathbf{b}$ $P D S$ silencing effectiveness: percent of leaves per plant with

constructs that can be evaluated. Petunia 'Picobella Blue' were inoculated at $20^{\circ} \mathrm{C}$ in the growth chamber. Plants remained in the growth chamber or were moved to the greenhouse at 0,4 , 7 and 10 days after inoculation. All plants $(n=8)$ inoculated with pTRV2-NbPDS showed some photobleaching. The plants that remained in the growth chamber for the duration of the experiment had the same photobleaching efficiency as the plants that were transitioned from the growth chamber to the greenhouse at $0,4,7$ and 10 days after inoculation (Fig. 7a). All plants inoculated with pTRV2-PhCHS showed some degree of $C H S$ silencing. $C H S$ silencing efficiency was $44 \%$ higher in plants that remained in the growth chamber for
CHS silencing (pTRV2-PhCHS)

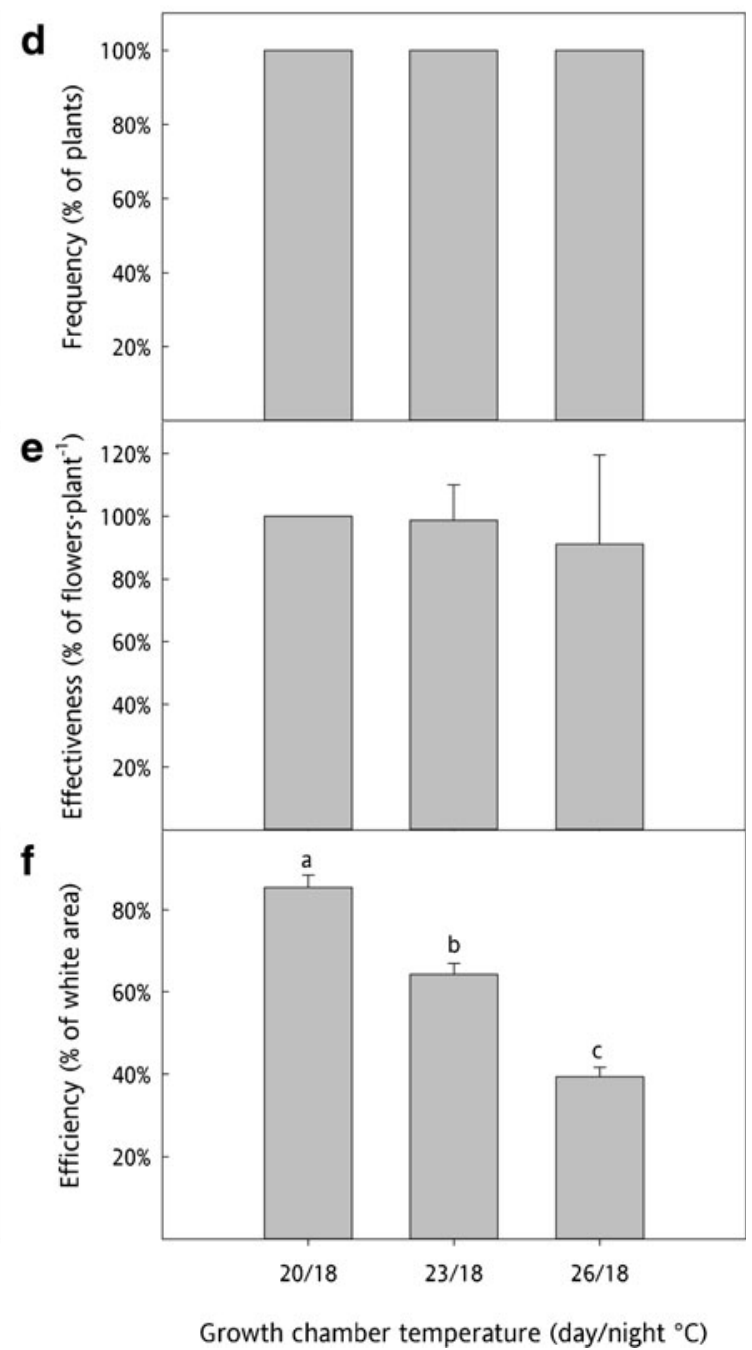

photobleaching. c $P D S$ silencing efficiency: extent of photobleaching per leaf quantified using WinCAM version 2007d (Regent Instrument Canada Inc.) image analysis software. d CHS silencing frequency: percent of plants that had corollas with white sectors. e CHS silencing effectiveness: percent of flowers per plant with white sectors. f $C H S$ silencing efficiency: extent of white sectoring per flower quantified using WinCAM. b, c Each bar represents the mean \pm SD. e, f Error bars represent $\mathrm{SE}$

the duration of the experiment. Plants that were transitioned to the greenhouse at day 0 exhibited significantly lower $C H S$ silencing than any other treatment (Fig. 7b).

\section{Discussion}

The location and amount of gene silencing within a plant can be highly variable when using viruses to induce silencing (Chen et al. 2004; Jiang et al. 2008). Environmental factors and inoculation methods (Chen et al. 2004; Jiang et al. 2011; Ryu et al. 2004; Spitzer et al. 2007; Wang et al. 2006; Wu et al. 
PDS silencing (pTRV2-NbPDS)

a
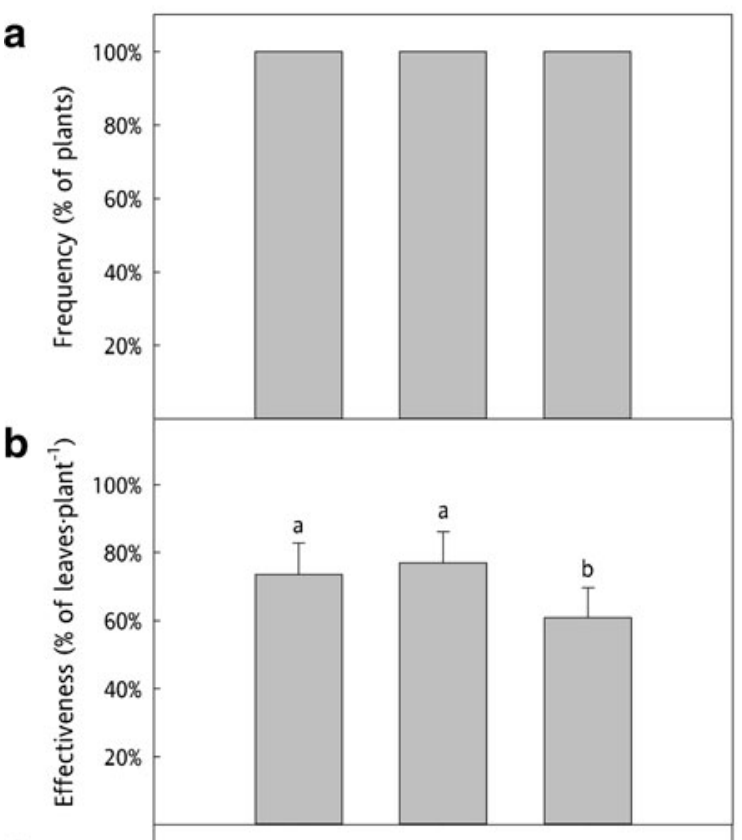

C

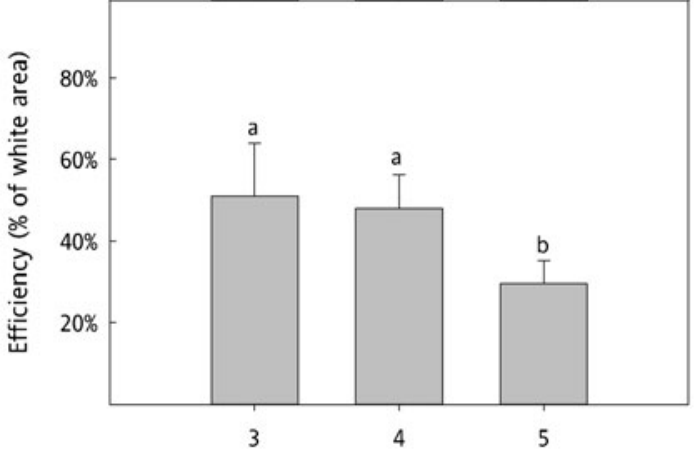

Seedling age at inoculation (weeks)

Fig. 5 Effects of seedling age at inoculation on $P D S$ and $C H S$ silencing. At 3, 4 and 5 weeks after sowing, Petunia $\times$ hybrida 'Picobella Blue' were inoculated $(n=10)$ with pTRV2-NbPDS or pTRV2-PhCHS. Gene silencing was estimated by measuring visible phenotypes of photobleaching (PDS silencing) in leaves and white sectoring in corollas (CHS silencing). a $P D S$ silencing frequency: percent of plants that exhibited photobleaching. b $P D S$ silencing effectiveness: percent of leaves per plant with photobleaching. c $P D S$ silencing efficiency: extent of

2011) can increase gene silencing variability. Some experiments, however, require more consistent, widespread and efficient silencing, which more closely resembles that of stably transformed knockout lines, to properly evaluate phenotypes. By using both pTRV2-NbPDS and pTRV2-PhCHS in conjunction with image analysis, we were able to optimize the techniques and environmental parameters for VIGS in petunia. Additionally, the efficiency of silenced phenotypes in both flowers and leaves increased significantly with these optimizations.

While proteins are a downstream result of transcription and translation, transcript abundance and protein quantities are not
CHS silencing ( $\mathrm{pTRV} 2-\mathrm{PhCHS}$ )

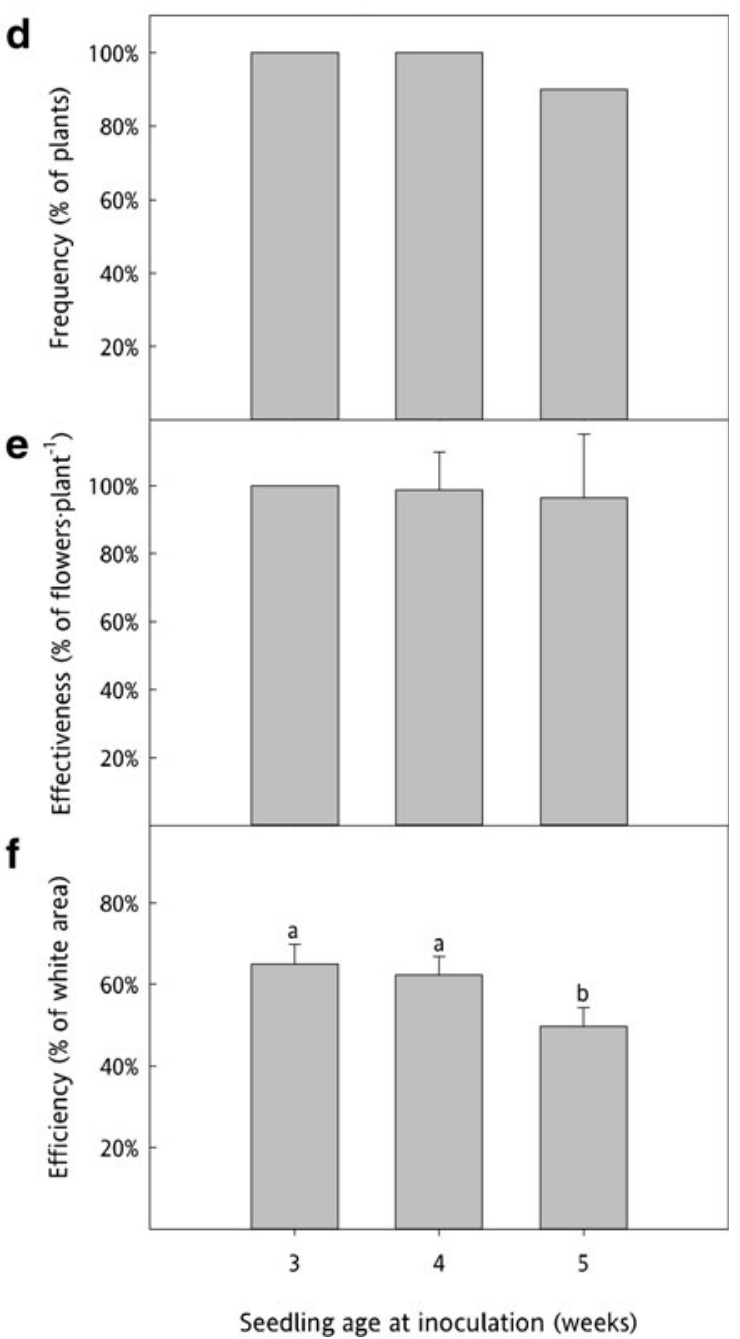

photobleaching per leaf quantified using WinCAM version 2007d (Regent Instrument Canada Inc.) image analysis software. d CHS silencing frequency: percent of plants that had corollas with white sectors. e $C H S$ silencing effectiveness: percent of flowers per plant with white sectors. $\mathbf{f}$ CHS silencing efficiency: extent of white sectoring per flower quantified using WinCAM. b, c Each bar represents the mean \pm SD. e, f Error bars represent $\mathrm{SE}$

always correlated. Gene silencing can occur through a combination of mRNA degradation and translational inhibition. Li et al. (2013) demonstrated that highly efficient gene silencing is often achieved more through translational repression than through transcript degradation. Our data also showed that in plant tissue exhibiting strong silencing phenotypes (e.g., $100 \%$ silencing), the transcript abundance of $P D S$ and $C H S$ was similar in tissue with less silencing (e.g., $62 \%$ or $41 \%$ ). Urso et al. (2013) found a similar discrepancy between PDS transcript abundance and photobleaching in grapes leaves. They concluded that it was ultimately more important to repress a target protein than its corresponding mRNA. The 


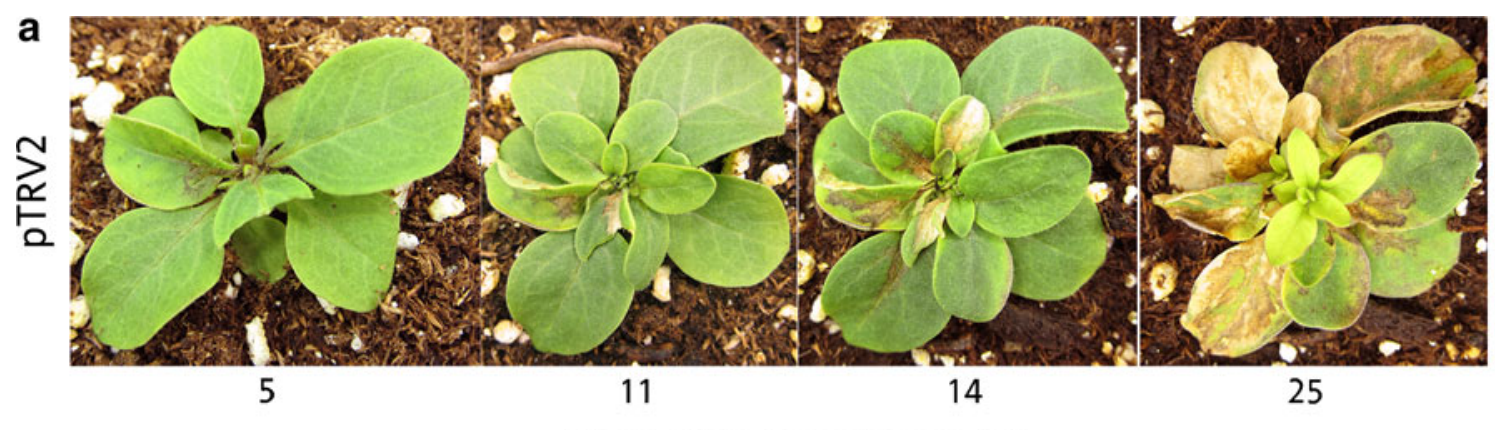

Time after inoculation (d)
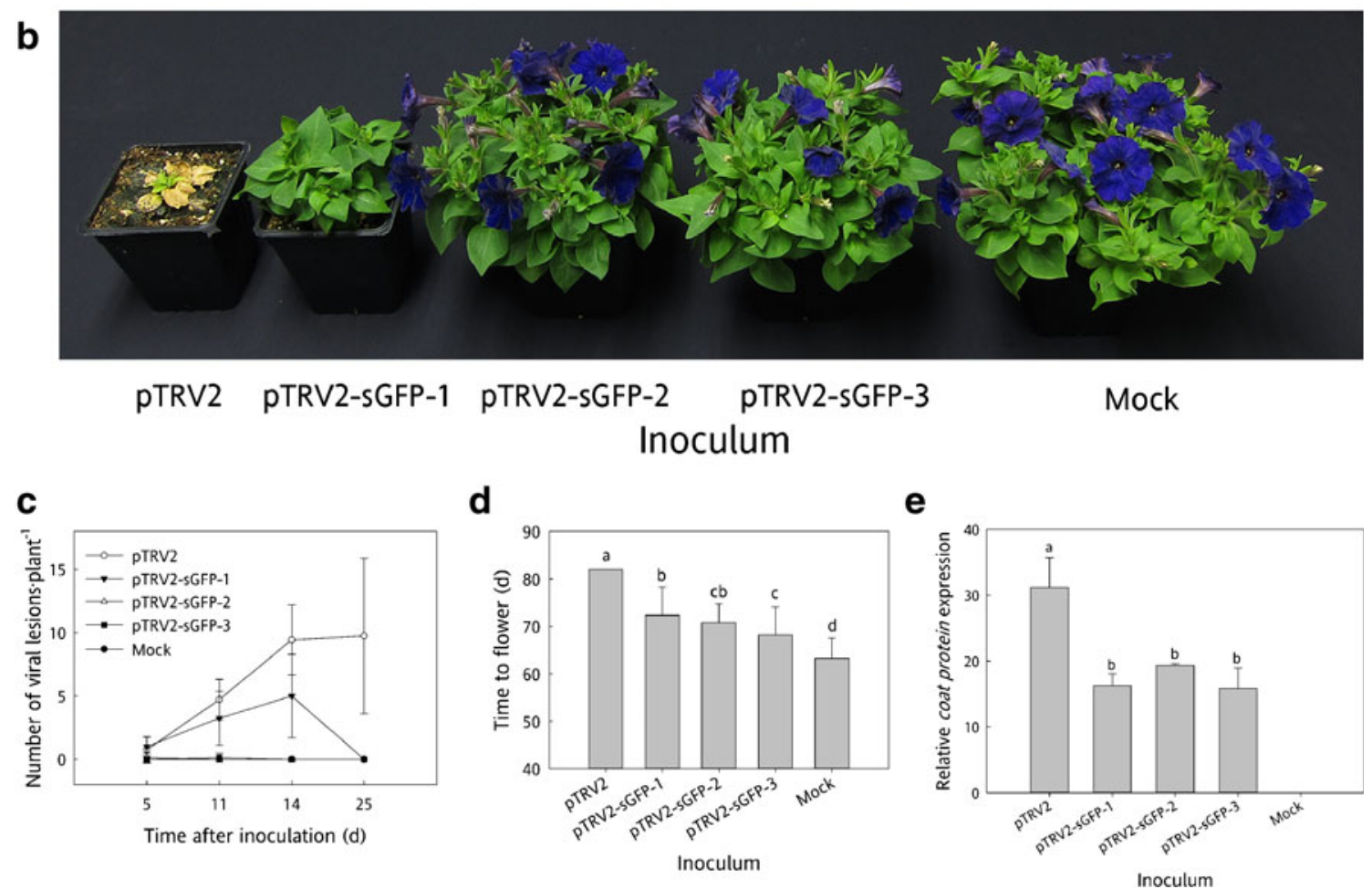

Fig. 6 Evaluation of control vectors for VIGS in Petunia $\times$ hybrida 'Picobella Blue'. a Leaf lesions at 5, 11, 14 and 25 days after inoculation with pTRV2 empty vector. b Viral symptom comparison among pTRV2 (empty vector), mock inoculation (Mock) and control constructs containing cloned fragments of $s G F P$ including pTRV2-sGFP-1 (198 bp), pTRV2-sGFP-2 (265 bp) and pTRV2-sGFP-3 (383 bp). c Lesion

development after inoculation with control vectors containing fragments of $s$ GFP. Line graph represents the mean visible lesions per plant \pm SD. d Effects of various inoculums on flowering times. e Relative TRV coat protein transcript abundance as determined by RT-qPCR. Gene expression was determined relative to PhACTIN. Bar graphs $(n=6)$ represent the mean $\pm \mathrm{SD}$

discrepancies between mRNA abundance and the extent of silencing phenotypes may be a result of translational repression. A higher correlation might be achieved if RT-qPCR methods could quantify the translationally active transcripts (Bustin et al. 2009; Li et al. 2013; Urso et al. 2013). Molecular validation of silencing, including $\mathrm{qPCR}$ and Western blot analyses, would be required to accurately correlate phenotypes with the down-regulation of specific genes, but phenotypic evaluation of $P D S$ and $C H S$ silencing provides an accurate means of optimizing VIGS protocols.

The standard method of counting the number of plants (i.e., frequency of silencing) and the number of leaves or flowers per plant that show silencing (i.e., effectiveness of silencing) does not take into account the sometimes very large differences in silencing within individual flowers and leaves. We found that silencing frequency provided the least accurate evaluation of the area of phenotypically visible silencing, and often no differences were detected among treatments. More differences were detected when photobleaching effectiveness was measured. The photobleaching effectiveness and efficiencies shared similar patterns across inoculation technique, temperature evaluation, and age of inoculation experiments. In some experiments, it may be sufficient to calculate the photobleaching effectiveness as an alternative to calculating photobleaching 
a

PDS silencing (pTRV2-NbPDS)

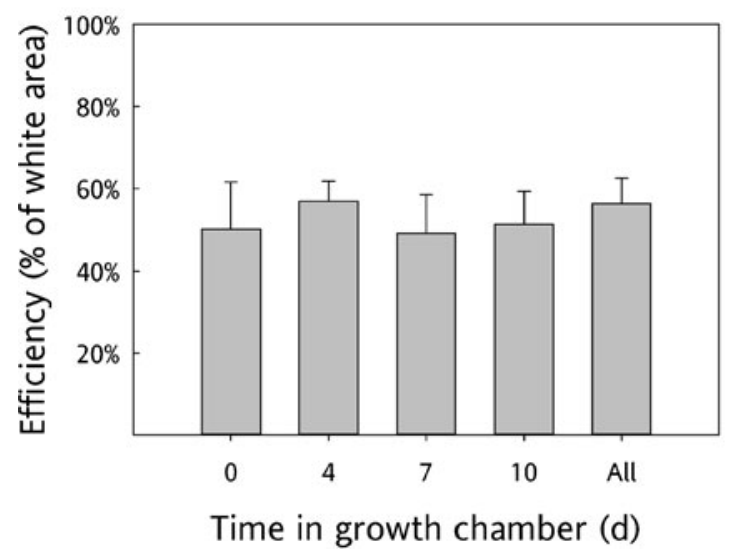

Fig. $7 P D S$ and $C H S$ silencing efficiencies in growth chamber and greenhouse environments. All Petunia $\times$ hybrida 'Picobella Blue' plants $(n=8)$ were inoculated with pTRV2-NbPDS or pTRV2-PhCHS in the growth chamber. Some plants remained in the growth chamber throughout the duration of the experiment (labeled 'All'), while others were moved to the greenhouse at $0,4,7$, or 10 days after inoculation. a $P D S$

efficiency. Image analysis is more time consuming than obtaining counts of whole plants (frequency), total leaves or flowers. In contrast to $P D S$ silencing results, the effectiveness and efficiency did not correlate in $C H S$ silenced plants. $C H S$ silencing effectiveness always corresponded with frequency and never with efficiency. This demonstrated that calculating silencing efficiencies (Eq. 3) may be critical in some VIGS applications. The image analysis software allowed us to more accurately quantify silencing efficiency across total leaves or flowers and to identify differences among treatments. This more accurate determination of silencing efficiency may be needed in some gene silencing experiments to explain why a phenotype is observed in some plants and not others that have been identified as having the same frequency or effectiveness of silencing.

The inoculation techniques of agroinfiltration and apical meristem application have both been used successfully in petunia VIGS experiments (Chen et al. 2004; Spitzer et al. 2007). Jiang et al. (2011) utilized agroinfiltration, but discussed the need to evaluate the apical meristem application further. Our research demonstrated that higher silencing occurred when using the apical meristem application. This method used a smaller volume of inoculum and required less time than agroinfiltration of the leaves. For example, approximately $200-400 \mu \mathrm{l}$ of inoculum was required for agroinfiltration of a young plant and it took approximately $15 \mathrm{~s}$. The apical meristem application only required $150 \mu \mathrm{l}$ and inoculation took approximately $5 \mathrm{~s}$ per plant. This procedure required the removal of the apical meristem, which induced axillary shoot development. This did not hinder silencing, but would not be suitable for studies involving gene expression in the shoot apical meristem. b $\quad$ CHS silencing ( $\mathrm{pTRV} 2-\mathrm{PhCHS}$ )

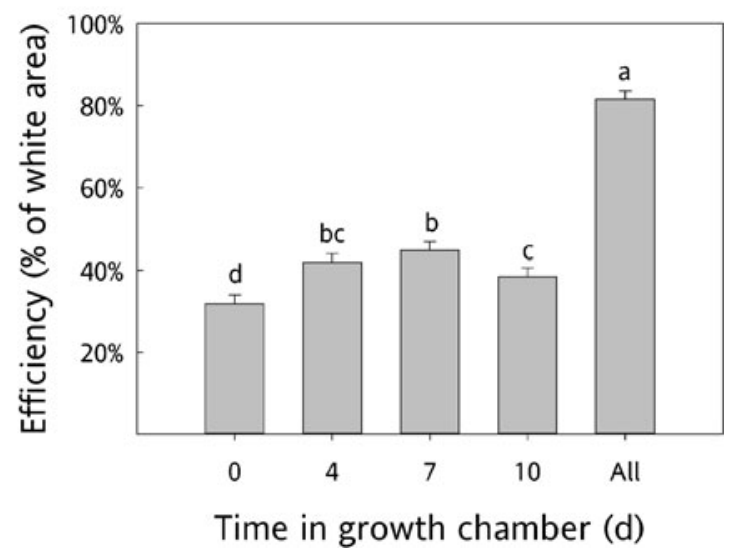

silencing efficiency among plants inoculated with pTRV2-NbPDS was quantified by image analysis software, WinCAM version 2007d (Regent Instrument Canada Inc.). Each bar represents the mean $\pm \mathrm{SD}$. b $C H S$ silencing efficiency among flowers of plants inoculated with pTRV2$P h C H S$ was quantified using WinCAM. Error bars represent SE

Differences in silencing patterns have been observed among petunia cultivars. From the eight cultivars tested, Chen et al. (2004) chose 'Fantasy Blue' to conduct their VIGS experiments because of consistent silencing and compact growth. Our research confirmed these results, and 'Fantasy Blue' received one of the best scores among the cultivars. 'Fantasy Blue' and 'Picobella Blue' may be from a similar genetic parentage and are morphologically indistinguishable. The differences we observed in silencing across the ten cultivars are most likely genetic. There could be single nucleotide polymorphisms (SNPs) that reduce homology between endogenous CHS and the CHS fragment in pTRV2. This could explain discrepancies between cultivars that scored well in $P D S$ photobleaching and poorly in $C H S$ silencing, such as 'Primetime Blue'. There could also be genetic differences (e.g., expression patterns or SNPs) in viral resistance or antiviral silencing machinery among cultivars. RNA-dependent RNA polymerase (RDRP) and Dicer-like enzymes are implicated in viral accumulation and antiviral silencing (Donaire et al. 2008). The identification of genetic differences in these gene families could be used in breeding programs to create cultivars that would be ideal for VIGS-based studies. Additionally, hypersensitive response to TRV in some potato lines has been attributed to a single, dominant resistance gene (Ghazala and Varrelmann 2007). Identifying resistance gene homologs to TRV in other solanaceous crops may also need to be considered for such a breeding program.

Useful viruses for VIGS must replicate quickly while suppressing the plant's silencing machinery. If silencing suppression is too strong then PTGS of the plant's endogenous gene will not occur. It has been shown that temperatures balance viral proliferation and small RNA accumulation (Szittya et al. 
2003). If temperatures are too high, then the virus will be unable to proliferate in the presence of increased antiviral activity, resulting in reduced levels of PTGS. For example, in $N$. benthaminana, higher temperatures induce stronger antiviral protection via RDRP6. As a result, higher quantities of small RNAs were quantified (Qu et al. 2005). This would hinder viral spread throughout the plant and reduce PTGS. Chen et al. (2004) and Spitzer et al. (2007) utilized temperatures of $25^{\circ} \mathrm{C}$ day $/ 20^{\circ} \mathrm{C}$ night for petunia VIGS experiments. We found that stronger silencing occurred at lower temperatures of $20^{\circ} \mathrm{C}$ day $/ 18^{\circ} \mathrm{C}$ night. For VIGS experiments, there may be a balance between viral proliferation and gene silencing. Additionally, lower temperatures during inoculation have been shown to increase the transformation efficiency of Agrobacterium (Dillen et al. 1997). This incubation period at cooler, controlled temperatures may increase transformation efficiencies and induce stronger PTGS.

Greenhouses usually offer more growing space, which would allow for more plants to be analyzed or screened; however, the environmental conditions of most greenhouses fluctuate with natural weather conditions. We wanted to determine if plants could be inoculated under optimized temperatures in the growth chamber and then moved to the greenhouse for phenotypic analysis. In our experiments, the greatest environmental difference between the greenhouse and growth chamber was temperature. The average temperature of the greenhouse gradually increased between March and June. $P D S$ silencing was not significantly different between growth chamber and greenhouse grown plants, but CHS silencing was dramatically different in these plants. Photobleaching was measured 3 weeks after inoculation and the average greenhouse temperature was $25{ }^{\circ} \mathrm{C}$. Once plants began to bloom (5 weeks after inoculation), $C H S$ silencing was measured over 4 weeks, and the average temperature during that time increased to $31^{\circ} \mathrm{C}$. These results are in agreement with our temperature evaluation, and suggest that cooler temperatures throughout plant growth are required to retain the best level of silencing. Good silencing may be achieved in the greenhouse only during a time of year when the greenhouse can be maintained at consistently cooler temperatures throughout the growth and evaluation of the plants.

Younger plant tissue is more susceptible to TRV infections (Wang et al. 2006), therefore, the stage of plant development at inoculation has a critical impact on the efficiency of subsequent gene silencing. We identified a window of 3-4 weeks after sowing that is ideal for inoculation. At 3 weeks, our petunias had three to five true leaves. Four-week-old seedlings had five to seven leaves. Two-week-old seedlings are easily damaged when handled and would be difficult to inoculate using the apical meristem method. Vacuum infiltration may be better suited for younger seedlings (Yan et al. 2012). At 5 weeks, petunias may be more resistant to Agrobacterium transformation or TRV infection, resulting in lower silencing.
TRV-based VIGS vectors have been widely used because they cause efficient gene silencing, while only causing mild viral symptoms (Burch-Smith et al. 2004). However, pTRV2 empty vector causes severe viral lesions in some plants (Brigneti et al. 2004; Ghazala and Varrelmann 2007; Hartl et al. 2008; Wu et al. 2011). The duplicated 35S promoter in pTRV2 (pYL156) increases viral symptoms, but improves gene silencing (Brigneti et al. 2004). We consistently observed strong viral symptoms and even death in petunias inoculated with this empty vector. Optimizing VIGS lead to more extreme viral symptoms in plants inoculated with empty vector, suggesting that the viral titer may be higher under these optimized conditions. In contrast, Chen et al. (2004) and Spitzer et al. (2007), who also used pYL156, did not report any severe viral symptoms after inoculating petunia with pTRV1/pTRV2. We were able to nearly eliminate viral symptoms in petunia by cloning a fragment of $s G F P$ into the pTRV2 vector. Wu et al. (2011) reported that a DNA fragment of approximately $250 \mathrm{bp}$ or more was sufficient to eliminate viral symptoms in tomatoes. We also demonstrated that 198 bp of $s G F P$ was not sufficient to eliminate viral necrosis and stunting, but that 265 and $383 \mathrm{bp}$ fragments were very effective. Our relative transcript abundance of TRV2 coat protein suggested that plants infected with pTRV2 empty vector have viral titer levels above a biological threshold that prohibits the plants from outgrowing leaf necrosis (observed in pTRV2-sGFP-1 inoculated plants) and avoiding death.

Our work demonstrates the importance of optimizing the VIGS protocol to a particular crop, because the experimental parameters currently utilized in various crops are diverse (e.g., Chen et al. 2004; Hartl et al. 2008; Ryu et al. 2004; Spitzer et al. 2007; Wang et al. 2006). This optimized protocol increased the area of silencing in two tissue types (leaves and corollas) and across two unrelated genes (CHS and $P D S$ ). Thus, we hypothesize that this protocol will increase silencing phenotypes in petunia for other GOIs. Furthermore, these improvements may enable VIGS results to be more consistent with stable transgenic knockdown or knockout lines. This work was carried out in petunia because it is a good model organism for studies of flower development (Gerats and Vandenbussche 2005), but the parameters optimized here may aid in the optimization of VIGS protocols for other crops. Additionally, petunia is a crop of high economic importance in horticultural markets and is related to several other high-value agronomic crops. Current VIGS methods in other crops may be improved by examining these protocols and utilizing image analysis software to more accurately quantify silencing and correlate this with observed phenotypes. VIGS is a powerful tool for reverse genetic studies, providing a rapid and highthroughput technique for the functional analysis of the thousands of genes that are currently being identified from microarray and RNA-seq experiments. 
Acknowledgments Salaries and research support were provided in part by State and Federal funds appropriated to the Ohio Agricultural Research and Development Center, The Ohio State University (Journal Article Number HCS 13-05). Research was also funded by the D. C. Kiplinger Endowment, The American Floral Endowment Gus Poesch Fund, and SEEDS: The OARDC Research Enhancement Competitive Grants Program. Additionally, we thank Dr. Dinesh-Kumar and Dr. Sophien Kamoun for providing VIGS vectors and Ball Horticultural Company and Syngenta for their petunia seed donations. We acknowledge the technical assistance of Laura Chapin and Eileen Ramsay.

Open Access This article is distributed under the terms of the Creative Commons Attribution License which permits any use, distribution, and reproduction in any medium, provided the original author(s) and the source are credited.

\section{References}

Al-Kaff NS, Covey SN, Kreike MM, Page AM, Pinder R, Dale PJ (1998) Transcriptional and posttranscriptional plant gene silencing in response to a pathogen. Science 279(5359):2113-2115

Benedito VA, Visser PB, Angenent GC, Krens FA (2004) The potential of virus-induced gene silencing for speeding up functional characterization of plant genes. Genet Mol Res 3(3):323-341

Brigneti G, Martín-Hernández AM, Jin H et al (2004) Virus-induced gene silencing in Solanum species. Plant J 39(2):264-272

Burch-Smith TM, Anderson JC, Martin GB, Dinesh-Kumar SP (2004) Applications and advantages of virus-induced gene silencing for gene function studies in plants. Plant J 39(5):734-746

Burch-Smith TM, Schiff M, Liu Y, Dinesh-Kumar SP (2006) Efficient virus-induced gene silencing in Arabidopsis. Plant Physiol 142(1): $21-27$

Bustin SA, Benes V, Garson JA et al (2009) The MIQE guidelines: minimum information for publication of quantitative real-time PCR experiments. Clin Chem 55(4):611-622

Caplan J, Dinesh-Kumar SP (2006) Using viral vectors to silence endogenous genes. Curr Protoc Microbiol I61:6.1-6.13. doi:10.1002/ 9780471729259.mc16i06s01

Chapin LJ, Jones ML (2009) Ethylene regulates phosphorus remobilization and expression of a phosphate transporter $(P h P T 1)$ during petunia corolla senescence. J Exp Bot 60(7):2179-2190

Chen J, Jiang C, Gookin T, Hunter D, Clark D, Reid M (2004) Chalcone synthase as a reporter in virus-induced gene silencing studies of flower senescence. Plant Mol Biol 55(4):521-530

Chen J, Jiang C, Reid MS (2005) Silencing a prohibitin alters plant development and senescence. Plant J 44(1):16-24

Dalmay T, Hamilton A, Mueller E, Baulcombe DC (2000) Potato Virus $X$ amplicons in Arabidopsis mediate genetic and epigenetic gene silencing. Plant Cell 12(3):369-379

Deng X, Elomaa P, Nguyen CX, Hytönen T, Valkonen J, Teeri TH (2012) Virus-induced gene silencing for Asteraceae - a reverse genetics approach for functional genomics in Gerbera hybrida. Plant Biotechnol J 10(8):970-978

Dillen W, De Clercq J, Kapila J, Zambre M, Van Montagu M, Angenon G (1997) The effect of temperature on Agrobacterium tumefaciensmediated gene transfer to plants. Plant J 12(6):1459-1463

Donaire L, Barajas D, Martínez-García B, Martínez-Priego L, Pagán I, Llave C (2008) Structural and genetic requirements for the biogenesis of Tobacco Rattle Virus-derived small interfering RNAs. J Virol 82(11):5167-5177

Fire A, Xu S, Montgomery MK, Kostas SA, Driver SE, Mello CC (1998) Potent and specific genetic interference by double-stranded RNA in Caenorhabditis elegans. Nature 391(6669):806-811
Gerats T, Vandenbussche M (2005) A model system comparative for research: Petunia. Trends Plant Sci 10(5):251-256

Ghazala W, Varrelmann M (2007) Tobacco rattle virus 29K movement protein is the elicitor of extreme and hypersensitive-like resistance in two cultivars of Solanum tuberosum. Mol Plant Microbe In 20(11): 1396-1405

Gould B, Kramer EM (2007) Virus-induced gene silencing as a tool for functional analyses in the emerging model plant Aquilegia (columbine, Ranunculaceae). Plant Methods 3(1):6

Grünewald K, Eckert M, Hirschberg J, Hagen C (2000) Phytoene desaturase is localized exclusively in the chloroplast and up-regulated at the mRNA level during accumulation of secondary carotenoids in Haematococcus pluvialis (Volvocales, Chlorophyceae). Plant Physiol 122(4):1261-1268

Hartl M, Merker H, Schmidt DD, Baldwin IT (2008) Optimized virusinduced gene silencing in Solanum nigrum reveals the defensive function of leucine aminopeptidase against herbivores and the shortcomings of empty vector controls. New Phytol 179(2):356-365

Hernandez-Garcia CM, Bouchard RA, Rushton PJ et al (2010) High level transgenic expression of soybean (Glycine max) GmERF and Gmubi gene promoters isolated by a novel promoter analysis pipeline. BMC Plant Biol 10:237

Hileman LC, Drea S, Martino G, Litt A, Irish VF (2005) Virus-induced gene silencing is an effective tool for assaying gene function in the basal eudicot species Papaver somniferum (opium poppy). Plant $\mathbf{J}$ 44(2):334-341

Hoffmann T, Kalinowski G, Schwab W (2006) RNAi-induced silencing of gene expression in strawberry fruit (Fragaria $\times$ ananassa) by agroinfiltration: a rapid assay for gene function analysis. Plant $\mathrm{J}$ 48(5):818-826

Jiang C, Lu F, Imsabai W, Meir S, Reid MS (2008) Silencing polygalacturonase expression inhibits tomato petiole abscission. J Exp Bot 59(4):973-979

Jiang C, Chen J, Reid M (2011) Virus-induced gene silencing in ornamental plants. In: RNAi and plant gene function analysis. Springer, pp 81-96

Kumagai M, Donson J, Della-Cioppa G, Harvey D, Hanley K, Grill L (1995) Cytoplasmic inhibition of carotenoid biosynthesis with virusderived RNA. Proc Natl Acad Sci U S A 92(5):1679-1683

Li J, Chung HS, Niu Y, Bush J, McCormack M, Sheen J (2013) Comprehensive protein-based artificial microRNA screens for effective gene silencing in plants. Plant Cell 25(5):1507-1522

Liu YL, Schiff M, Dinesh-Kumar SP (2002a) Virus-induced gene silencing in tomato. Plant J 31(6):777-786

Liu YL, Schiff M, Marathe R, Dinesh-Kumar SP (2002b) Tobacco Rarl, EDS1 and NPRI/NIM1 like genes are required for $N$-mediated resistance to tobacco mosaic virus. Plant J 30(4):415-429

Lu R, Martin-Hernandez AM, Peart JR, Malcuit I, Baulcombe DC (2003) Virus-induced gene silencing in plants. Methods 30(4): 296-303

Mallona I, Lischewski S, Weiss J, Hause B, Egea-Cortines M (2010) Validation of reference genes for quantitative real-time PCR during leaf and flower development in Petunia hybrida. BMC Plant Biol 10:4

Muruganantham M, Moskovitz Y, Haviv S et al (2009) Grapevine virus $A$-mediated gene silencing in Nicotiana benthamiana and Vitis vinifera. J Virol Methods 155(2):167-174

Napoli C, Lemieux C, Jorgensen R (1990) Introduction of a chimeric chalcone synthase gene into petunia results in reversible cosuppression of homologous genes in trans. Plant Cell 2(4):279-289

Qu F, Ye X, Hou G, Sato S, Clemente TE, Morris TJ (2005) RDR6 has a broad-spectrum but temperature-dependent antiviral defense role in Nicotiana benthamiana. J Virol 79(24):15209-15217

Ryu C, Anand A, Kang L, Mysore K (2004) Agrodrench: a novel and effective agroinoculation method for virus-induced gene silencing in roots and diverse solanaceous species. Plant J 40(2):322-331 
Saedler R, Baldwin I (2004) Virus-induced gene silencing of jasmonateinduced direct defences, nicotine and trypsin proteinase-inhibitors in Nicotiana attenuata. J Exp Bot 55(395):151-157

Senthil-Kumar M, Hema R, Anand A, Kang L, Udayakumar M, Mysore KS (2007) A systematic study to determine the extent of gene silencing in Nicotiana benthamiana and other Solanaceae species when heterologous gene sequences are used for virus-induced gene silencing. New Phytol 176(4):782-791

Sharma B, Kramer EM (2013) Virus-induced gene silencing in the papid cycling columbine Aquilegia coerulea "Origami”. In: Virus-induced gene silencing. Springer, New York, pp 71-81

Sharma PC, Ito A, Shimizu T, Terauchi R, Kamoun S, Saitoh H (2003) Virus-induced silencing of WIPK and SIPK genes reduces resistance to a bacterial pathogen, but has no effect on the INF1-induced hypersensitive response (HR) in Nicotiana benthamiana. Mol Genet Genomics 269(5):583-591

Spitzer B, Zvi MMB, Ovadis M et al (2007) Reverse genetics of floral scent: application of tobacco rattle virus-based gene silencing in petunia. Plant Physiol 145(4):1241-1250

Spitzer-Rimon B, Marhevka E, Barkai O et al (2010) EOBII, a gene encoding a flower-specific regulator of phenylpropanoid volatiles' biosynthesis in petunia. Plant Cell 22(6):1961-1976

Szittya G, Silhavy D, Molnar A et al (2003) Low temperature inhibits RNA silencing-mediated defence by the control of siRNA generation. EMBO J 22(3):633-640
Urso S, Zottini M, Ruberti C et al (2013) An Agrobacterium tumefaciensmediated gene silencing system for functional analysis in grapevine. Plant Cell Tiss Org 114(1):49-60

Van Kammen A (1997) Virus-induced gene silencing in infected and transgenic plants. Trends Plant Sci 2(11):409-411

Wang C, Cai X, Wang X, Zheng Z (2006) Optimisation of tobacco rattle virus-induced gene silencing in Arabidopsis. Funct Plant Biol 33(4): 347-355

Watson JM, Fusaro AF, Wang M, Waterhouse PM (2005) RNA silencing platforms in plants. FEBS Lett 579(26):5982-5987

Wege S, Scholz A, Gleissberg S, Becker A (2007) Highly efficient virusinduced gene silencing (VIGS) in California poppy (Eschscholzia californica): an evaluation of VIGS as a strategy to obtain functional data from non-model plants. Ann Bot 100(3):641-649

Wu C, Jia L, Goggin F (2011) The reliability of virus-induced gene silencing experiments using tobacco rattle virus in tomato is influenced by the size of the vector control. Mol Plant Pathol 12(3):299-305

Xu X, Jiang C, Donnelly L, Reid MS (2007) Functional analysis of a RING domain ankyrin repeat protein that is highly expressed during flower senescence. J Exp Bot 58(13):3623-3630

Yan H, Fu D, Zhu B, Liu H, Shen X, Luo Y (2012) Sprout vacuuminfiltration: a simple and efficient agroinoculation method for virusinduced gene silencing in diverse solanaceous species. Plant Cell Rep 31(9):1713-1722 